Int. J. Electrochem. Sci., 13 (2018) $8222-8240$

\title{
A promising hydroxyapatite/graphene hybrid nanocomposite for methylene blue dye's removal in wastewater treatment
}

\author{
Mohamed A. Hassan ${ }^{1}$, Ahmad M. Mohammad, ${ }^{2,}$, Taher A. Salaheldin ${ }^{1,3}$, Bahgat E. El-Anadouli, ${ }^{2 *}$ \\ ${ }^{1}$ Nanotechnology and Advanced Materials Central Laboratory, Agriculture Research Center, Giza, \\ Egypt \\ ${ }^{2}$ Chemistry Department, Faculty of Science, Cairo University, PO 12613 Giza, Egypt \\ ${ }^{3}$ Nanotechnology Research Centre, British University in Egypt, Egypt \\ *E-mail: ammohammad@cu.edu.eg, bahgat@sci.cu.edu.eg
}

doi: $10.20964 / 2018.08 .77$

Received: 17 February 2018 / Accepted: 12 April 2018 / Published: 5 July 2018

\begin{abstract}
A novel hydroxyapatite/graphene hybrid nanocomposite (HAp/G) was developed as a competent adsorbent for the removal of methylene blue (MB) dye in wastewater treatment. The adsorption was pursued in a batch process that followed pseudo-second-order kinetics. Several techniques including the high resolution transmission electron microscopy (HR-TEM), energy dispersive X-ray analysis (EDX), X-ray diffraction (XRD), Fourier transform infrared spectrophotometry (FTIR) and Zeta potential (Electrokinetic potential) measurements were employed to evaluate the topography, composition, crystal structure, functionality and stability of the developed sorbent. The equilibrium concentration of MB was estimated using UV-Vis spectrophotometry. The impact of MB's initial concentration, HAp/G's dosage and solution $\mathrm{pH}$ on the adsorption capacity of HAp/G was investigated. Interestingly, superior removal efficiencies (up to 99.9\%) for MB were obtained using HAp/G. Typically, the maximum sorption capacity $\left(q_{m}\right)$ of $\mathrm{HAp} / \mathrm{G}$ to MB was $333.3 \mathrm{mg} / \mathrm{g}$, which excelled several previously-reported achievements at other sorbents. The harmony of data fitting with the Langmuir isotherm was successful.
\end{abstract}

Keywords: Wastewater; Graphene composites; Adsorption; Dyes; Langmuir.

\section{$\underline{\text { FULL TEXT }}$}

(C) 2018 The Authors. Published by ESG (www.electrochemsci.org). This article is an open access article distributed under the terms and conditions of the Creative Commons Attribution license (http://creativecommons.org/licenses/by/4.0/). 